\title{
Evaluation of the Established IoT Smart Home Robot Teaching Module Based on Embedded Thematic-Approach Strategy
}

\author{
Kai-Chao Yao ${ }^{D}$, Wei-Tzer Huang, Li-Chiou Hsu, Chin-Kun Yang, and Jian-Yuan Lai \\ Department of Industrial Education and Technology, National Changhua University of Education, No. 2 Shi-Da Road, \\ Changhua, Taiwan \\ Correspondence should be addressed to Kai-Chao Yao; kcyao@cc.ncue.edu.tw
}

Received 15 October 2020; Revised 9 November 2020; Accepted 3 December 2020; Published 22 December 2020

Academic Editor: Ching-Hsin Wang

Copyright ( $\odot 2020$ Kai-Chao Yao et al. This is an open access article distributed under the Creative Commons Attribution License, which permits unrestricted use, distribution, and reproduction in any medium, provided the original work is properly cited.

Artificial intelligence (AI) technology-based intelligent robots are constructed using different technologies, such as Internet of Things (IoT), big data, deep learning, machine learning, neural network, and expert system. This particular type of robots can increase the work efficiency of humans and improve their quality of life. From the industry perspective, AI robots possess unlimited potential for development, and they are projected to be a 10-trillion-dollar industry. In this study, the critical technology of IoT is applied to develop a teaching module for an IoT smart home robot. Teaching and evaluation are performed through an embedded thematic-approach teaching strategy in the course named Automatic Measurement and Monitoring. This research aims to teach students how to integrate IoT technology into robot design and construction to build IoT smart home robots. This cross-disciplinary research incorporates emerging technology-integration of smart home, robot construction, and IoT technologies-into industrial education, teaching material and equipment development, and experimental teaching and evaluation. The participating students were juniors or seniors from the Department of Electrical Engineering or Electromechanical Engineering at the University of Technology.

\section{Introduction}

International Data Corporation (IDC), an international company that performs investigation, market analysis, and consulting, had predicted that $45 \%$ of the emerging robots in 2020 will possess at least one intelligent function, such as prediction analysis, machine learning (ML), or image recognition. This advancement is critical to research on artificial intelligence (AI) robots. According to IDC's prediction, robotic features will evolve in course of the robot development process, undergoing the stages of mechanical operation, big data analysis, and AI. Moreover, one of the main robotics applications involves building AI robots for use in houses to improve the quality of life of humans $[1,2]$.

In recent years, AI technology has become more advanced, and various service robots have been increasingly developed, such as Amazon Echo, Google Home, and Jibo. Taiwan's ICT giants are also developing smart service robot layouts, such as Pepper by Foxconn, Zenbo by Asus, and
ADATA ibotn by ADATA. Building AI-based intelligent robots requires the integration of various technologies such as the Internet of Things (IoT), big data, deep learning, ML, neural network, and expert system. These intelligent robots can improve the work efficiency of humans and their quality of life. They have tremendous potential for development and are projected to be a 10-trillion-dollar industry. Within the technical framework for integrating AI with IoT, the Internet of Everything (IoE) architecture becomes more complicated, requiring a large number of IoT hardware and software integrations.

The huge amount of data (big data) produced requires the continuous improvement of ML technology, promoting the rapid development of advanced algorithms. This also promotes the development of different types of IoT smart robots. In Taiwan, robotics education has attracted considerable attention in the past 10 years due to the growing demand for the related talent in the industry. Focused professional skills have been incorporated into student 
learning at the University of Technology [3]. Currently, the government and business communities are investing their resources for talent development in the domain of robotics education [4]. Colleges and universities are the current education centers and resources for robotics in Taiwan. Elementary schools, junior high schools, and senior high schools do not offer formal courses on robotics education. The only channel for the exposure of students to robotics education is through participation in robot clubs in schools or by attending cram schools for robotics education. This research not only provides the industry with talent but also trains learners for promoting robotics education. Determining the effectiveness of robotics education is also one of the objectives and motivations of this research.

Smart homes are equipped with systems integrated with information collection, network transmission, and other user-friendly services as well as home appliance automation and smart management, providing user-residents with a convenient, safe, and warm living environment. In smart homes, devices can be humanized through various sensors. The device sends messages to the user, which helps the users and family to effectively exchange information and establish a well-coordinated family environment $[5,6]$. In this research, a myRIO controller and Laboratory Virtual Instrument Engineering Workbench (LabVIEW) are used to integrate robotics with IoT for building an IoT smart home robot. Additionally, teaching material is developed for thematic teaching [7].

In thematic teaching (also known as thematic instruction), a theme is selected and highlighted through an instructional unit or module, a course, or multiple courses. It is often interdisciplinary in nature, highlighting the relationship between academic disciplines and its connection with everyday life. This teaching method has been adopted by previous studies: [8] used the concept for tablet-based science education, [9] examined how a Chinese teacher thematically constructed six nascent entrepreneurs to illustrate the concept of entrepreneurship in a classroom setting, [10] indicated that the thematic teaching of gross anatomy and anatomical knowledge as well as teaching confidence can benefit first-year students, and [11] aimed to identify patterns and trends prevalent in engineering education by analyzing how research has evolved in relevant engineering education publications. Thematic teaching can be of great value in sustainable application of engineering education. Thematic embedded teaching is a teaching strategy designed mainly for the experimental teaching and the evaluation of thematic curriculum modules in homogenous classrooms [12]. With this design, new courses need not be introduced just to evaluate a specific teaching content. This approach helps implement a product-oriented teaching strategy model through homogenous courses with the same technical core.

Thematic teaching is an approach for teaching and learning, whereby different segments of a curriculum are connected together and integrated following a theme. Usually, teaching evaluation follows thematic teaching in the same course $[13,14]$. However, in this research, thematicapproach teaching and evaluation cooccur for the IoT smart home robot teaching module in the experimental course named Automatic Measurement Technology [15]. Psychomotor and affective evaluation forms are developed and utilized to understand the teaching results. Based on this approach, the teaching evaluation of the IoT smart home robot module can be simplified.

Assessment is integral to student learning at the higher education level, with a strong influence on student experience. Various methods exist for teaching evaluation in higher education; different evaluation models are used to understand the effectiveness of teaching depending on the concerned field and evaluation connotations. For example, [16] used dialogic feed-forward assessment to improve the student learning experience. In addition, [17] proposed an analytical framework for creating and interpreting assessments across higher education disciplines and suggested that assessments can be categorized based on objectives, formats, modes, and group arrangements. The assessment experience questionnaire has been widely adopted to measure conditions of learning through assessment. It is one of three methods used in transforming the experience of students through assessment research process [18]. To evaluate the effectiveness of teaching in the evaluation process, the effectiveness and stability of the evaluation tools should be verified [19]. Based on the literature review, this research applies the thematic-approach teaching model and rating scale type evaluation.

\section{Preliminaries}

The Robot Design and Practice course has been established for college-level robotics education. myRIO and LabVIEW, which are frequently applied in the industry, are combined and proposed as the core equipment of this course. This technology-based course is designed for engineering and technology fields at the University of Technology. Course indicators are provided in the form of a Delphi questionnaire, which is drafted based on literature review, expert consultations, and interviews. Four indicator dimensions are presented for chapter titles, 21 first-level course indicators for section titles and 62 second-level course indicators for lesson titles. Analytic hierarchy process (AHP) is utilized to determine the time allocation for each chapter [20, 21]. Four types of robots are proposed and constructed to demonstrate hardware and software integration.

According to the difficulty levels of property and equipment training, course arrangement order is designed in three levels: (i) basic concepts and skills, focusing on robot technology and LabVIEW design; (ii) expanded concepts and skills, focusing on myRIO Technology; and (iii) advanced applications, focusing on robot design and implementation.

Table 1 presents the teaching schedule. By applying AHP, the weight of each subject chapter is transformed into teaching hours. In Table 1, the schedule and time allocation for each chapter and section are listed based on the weightto-hour transformation. To strengthen the designed course's industrial relevance, two expert lectures are scheduled during the semester based on the Delphi questionnaire. Four types of robots are designed in the robot design and 
TABle 1: Schedule design for chapters and sections of Robot Design and Practice course.

\begin{tabular}{|c|c|c|c|}
\hline Chapter subject & Section outline & Time & Note \\
\hline Robot technology & $\begin{array}{c}\text { 1-1. Evolution of robots } \\
\text { 1-2. Present and future of robotics industry } \\
1-3 \text {. Current robot technology } \\
1-4 \text {. Robotics education } \\
1-5 \text {. Robot structure and design }\end{array}$ & 2 weeks/ $6 \mathrm{~h}$ & \\
\hline LabVIEW design & $\begin{array}{c}\text { 2-1. LabVIEW program } \\
\text { 2-2. Usage and test for various loops } \\
\text { 2-3. Usage and test for array and data } \\
\text { 2-4. Usage and test for graphics and charts } \\
2-5 \text {. Usage and test for string and file I/O function } \\
\text { 2-6. I/O interface of signal transmission } \\
\text { 2-7. Functions of remote control } \\
\text { 2-8. Tool palette of NI myRIO }\end{array}$ & 3 weeks/9h & Expert lecture \\
\hline myRIO technology & $\begin{array}{l}\text { 3-1. Using NI myRIO } \\
\text { 3-2. Integration of sensor with myRIO } \\
\text { 3-3. Integration of controlled devices with myRIO } \\
\text { 3-4. Integration of additional devices with myRIO }\end{array}$ & 5 weeks/15h & Expert lecture \\
\hline Robot design and implementation & $\begin{array}{l}\text { 4-1. Wheel robot design and construction } \\
\text { 4-2. Balance arm design and construction } \\
\text { 4-3. Self-balancing two-wheel robot design and construction } \\
\text { 4-4. KNR robot design and construction }\end{array}$ & 8 weeks $/ 24 h$ & $\begin{array}{l}\text { Topics of } \\
\text { thematic teaching }\end{array}$ \\
\hline
\end{tabular}

Remark. 18 weeks/54 h/semester.

implementation chapter for thematic teaching based on the other three chapters [22].

The embedded thematic-approach teaching strategy is applied to evaluate the experimental teaching process of the IoT smart home robot teaching module. The subject robot design and implementation will be taught in the developed IoT smart home robot teaching module. The embedded thematic teaching strategy model presented in Figure 1 is embedded into the Automatic Measurement Technology course, which is a homogenous course with the same technical core as the Robot Design and Practice course. The advantage of this teaching strategy is that it eliminates the need for a new course for evaluation and is thus time-efficient. The disadvantage is that the evaluation results represent an approximate assessment. Moreover, this teaching strategy is contingent on certain conditions: (i) both courses must share the same core technology and (ii) both courses must have a product-oriented course structure. A productoriented course structure is one where the product is built at the end of the course.

\section{Methodology}

The IoT smart home robot teaching module and teaching material were developed in this research. After developing the teaching material, experts reviewed whether its content aligns with the teaching objectives to establish the integrity and appropriateness of the teaching material. This thematic teaching content was delivered through experimental teaching in the Automatic Measurement and Monitoring course. In this experimental teaching process, an embedded thematic-approach strategy was applied. The psychomotor scale and affective scales were developed for teaching evaluation. The experimental research method and the cooperation scale survey method were used to determine the students' acceptance rate and professional relevance of this theme-based IoT smart home robot teaching module. Guided by the research purpose, the research was conducted through the following steps:

(1) Establishment and planning of the thematic IoT smart home robot teaching module: the teaching module and teaching material for the IoT smart home robot technology thematic unit were developed.

(2) Expert review: experts were invited to review the teaching material of the IoT smart home robot module; the experts comprised three professors with expertise in robotics, industrial education, and industrial robots.

(3) Expert validity: validity was tested against the skills and affective assessment scale.

(4) Kendall Harmony Coefficient was used to test the reliability of the skill assessment form.

(5) Cronbach $\alpha$ was used to test the reliability of the sentiment questionnaire.

(6) Thematic teaching: the teaching followed a targeted theme.

\section{Main Results}

4.1. Teaching Module and Teaching Material. This thematic IoT smart home robot teaching module was constructed by applying LabVIEW and myRIO. The robot construction was based on a mobile carrier that could be controlled through the 


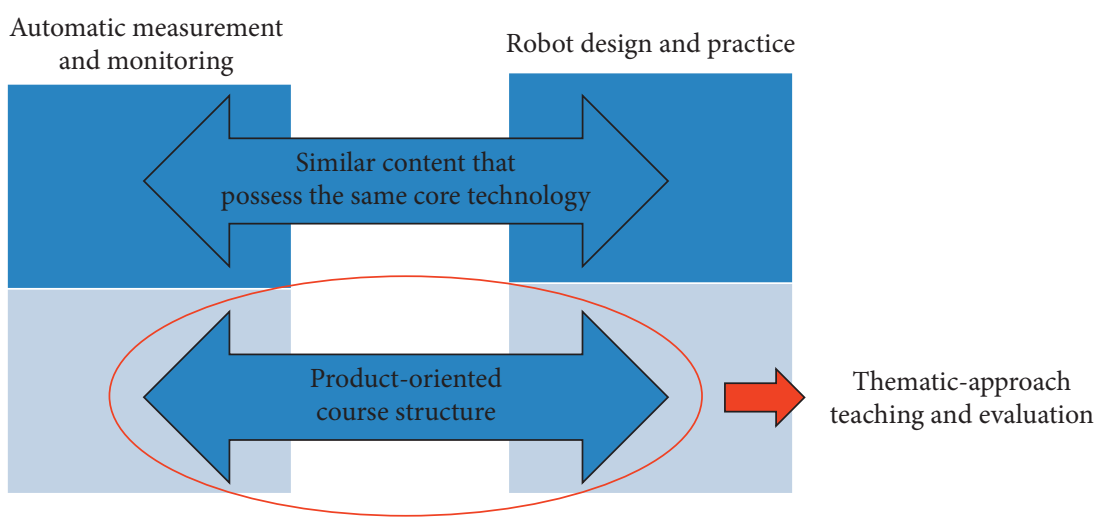

Figure 1: Thematic-approach teaching model.

Internet or local Wi-Fi, because LabVIEW offers an embedded remote control function. LabVIEW is a system-design platform and development environment for visual programming languages. It is also typically used for data acquisition, instrument control, and industrial automation of various operating systems, such as Microsoft Windows and different versions of Unix, Linux, and macOS [7, 23]. myRIO is a realtime embedded board that requires LabVIEW. myRIO is used to develop applications that utilize its onboard FPGA and microprocessor, and it is focused on basic control applications [24]. In [25], a robot carrier similar to that in the present research was constructed. In [26], a smart home design was developed utilizing myRIO and LabVIEW. Furthermore, in [27], the same equipment was used to achieve machine vision for practical use. Additionally, instructional robots have featured in many research papers [28-30]. However, none of the robots were integrated with AI. In the present research, robotics, IoT, smart home, and wireless communication technologies were utilized to build a mobile smart home robot possessing the characteristics of AI. The further development of this smart robot can integrate Python with its built-in AI module and algorithm to analyze obtained data and images. This way will create more powerful AI functions. ANN (Artificial Neural Network), CNN (Convolutional Neural Network), and RNN (Recurrent Neural Network) are all often applied to proceed the reinforcement. Figure 2 demonstrates the system structure of IoT smart home robots. The structure of the robot is made of aluminum alloy, and its components are printed using a $3 \mathrm{D}$ printer. The hardware components comprise a myRIO controller, a gripper, and a steerable webcam. The robot can sense physical signals, and a $\mathrm{Wi}-\mathrm{Fi}$ relay is coordinated to perform the switch control of home appliances. The robot can be controlled directly using a PC and remotely through the local $\mathrm{Wi}$-Fi or Internet. An automatic cruising mode is designed to help the system perform mobile monitoring functions. Moreover, the robot is provided with image recognition functionality for detecting specific or suspicious subjects.

Figure 3 demonstrates the control structure of the mobile smart home robots. The following are the five major components of the system: path memorizing, real-time image recognition functions, sensor monitoring, remote relays, and Line notification. Data transmission occurs between the servo host and the controller, myRIO, through Wi-Fi. Due to the path memorizing functionality, the robot can memorize the cruising path; thus, cruising path presets are possible in the robot. Due to the real-time image recognition function, the robot can monitor real-time images and utilize the image deduction method to perform unknown subject detection function. Equipped with sensor monitoring, the robot has five sensors for sensing temperature, illuminance, humidity, IR, and vibrations. In case of remote relays, USR-IO88 $\mathrm{Wi}$-Fi relays are applied to remotely control house appliances through the robot. By integrating Line notifications, all reactions from the sensors are notified to the household owner through Line.

Figure 4 demonstrates the front control and display panel of the robot. Block A consists of the time stamp, movement control, and cruising mode settings that can outline an automatic cruising path for mobile monitoring. Block B displays the data of the IR, light, humidity, illuminance, and temperature sensors. Block $\mathrm{C}$ displays realtime images from the steerable cam, which uses the image recognition feature for detecting specific or suspicious subjects. Block D consists of the buttons for movement commands and steering the webcam's directions for capturing images. Block E demonstrates the output display of a three-axis accelerometer to interpret the robot's movement directions. Figure 5 shows the exterior of the mobile smart home robot.

Based on the teaching module, the teaching material comprises six units: overview, IoT smart home robot technology, IoT smart home robot system, establishment and practice of IoT smart home robot technology, conclusion, and assignments and challenges. Moreover, based on the control structure of the IoT smart home robot and expert consultations, the following six technical capability indicators are established: (i) software design, (ii) use of the controller, (iii) hardware construction, (iv) software and hardware system integration, (v) IoT technology practice, and (vi) system operation.

4.2. Experimental Class Implementation and Evaluation. The experimental class was offered as a requirement for the fall 2019 semester in the Department of Industrial Education 


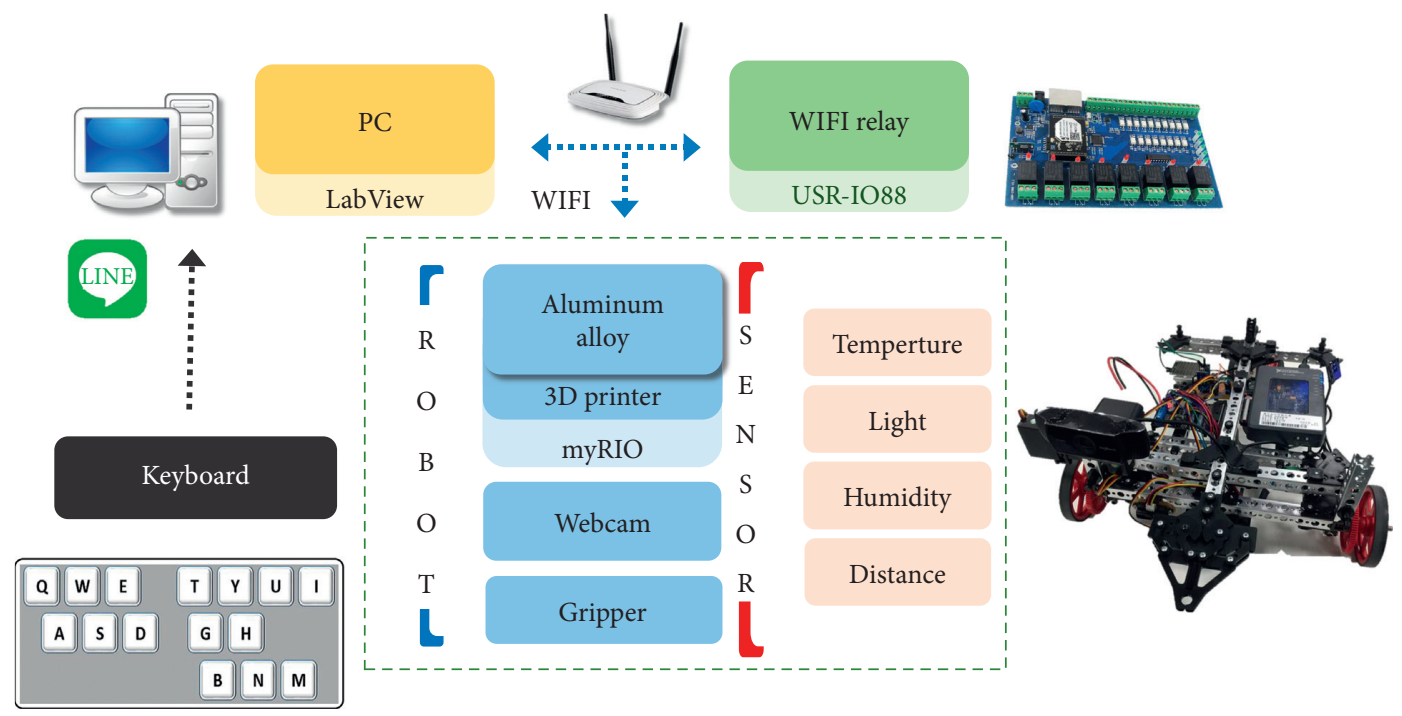

FIGURE 2: System structure of mobile smart home robots.

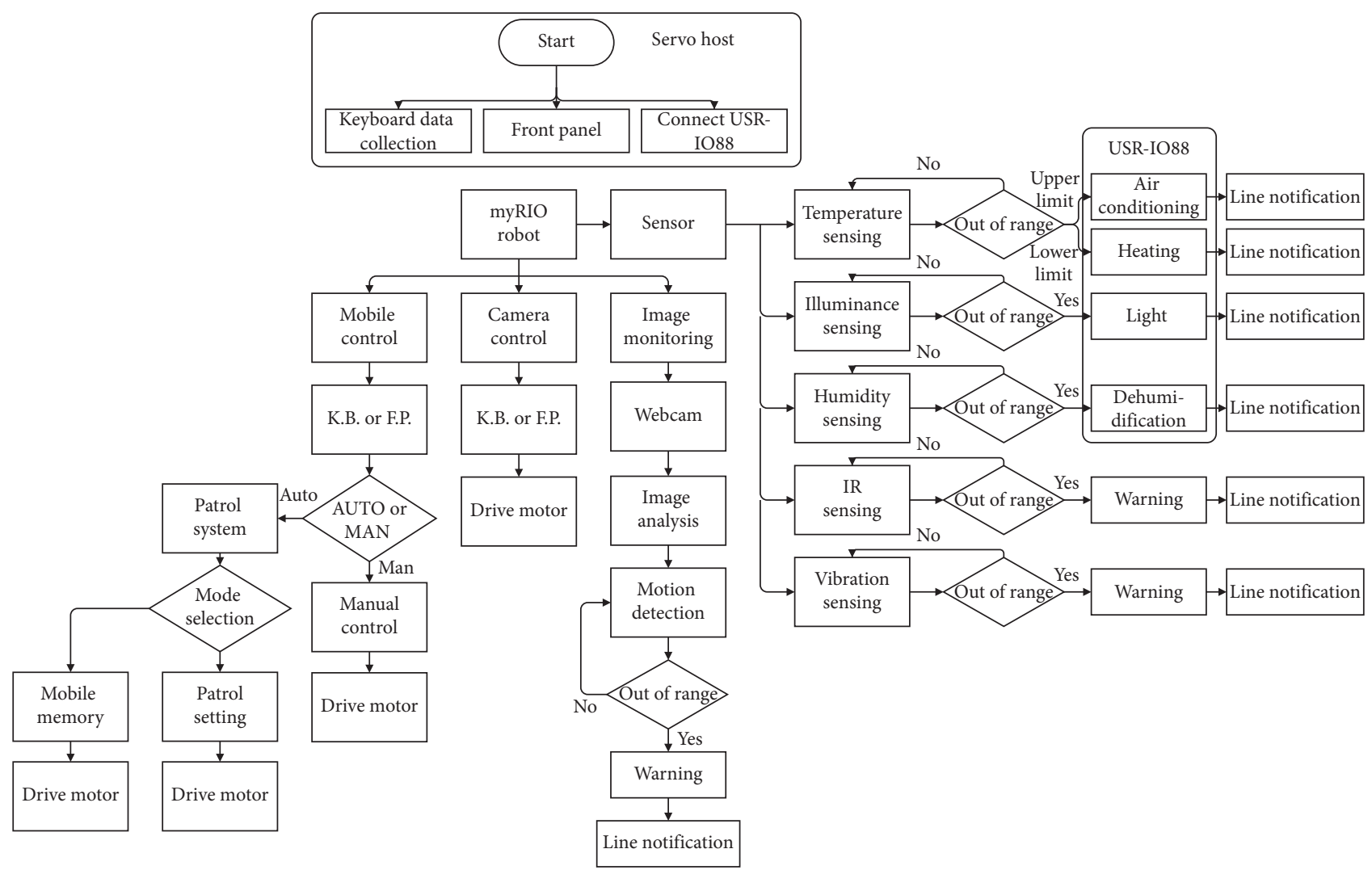

FIgURE 3: Control structure of mobile smart home robots.

and Technology, National Changhua University of Education, Taiwan. This course was called Automatic Measurement Technology, taught for $3 \mathrm{~h}$, and worth 3 credits. A total of 39 students enrolled into the class.

A quasi-experimental design was applied in the teaching experiment because of the newly developed teaching material and equipment. Pre- and posttest design methods were used in this course evaluation [31]. Bloom proposed the taxonomy for educational objectives in 1956 [32]. According to this theory, this evaluation involved two of three major domains, namely, psychomotor and affective domains. Therefore, the developed and designed evaluation forms comprised the psychomotor and affective scales. Figure 6 demonstrates the schedule for the formal evaluation of the two domains. Table 2 presents the unit and progress of teaching material in experimental teaching. 


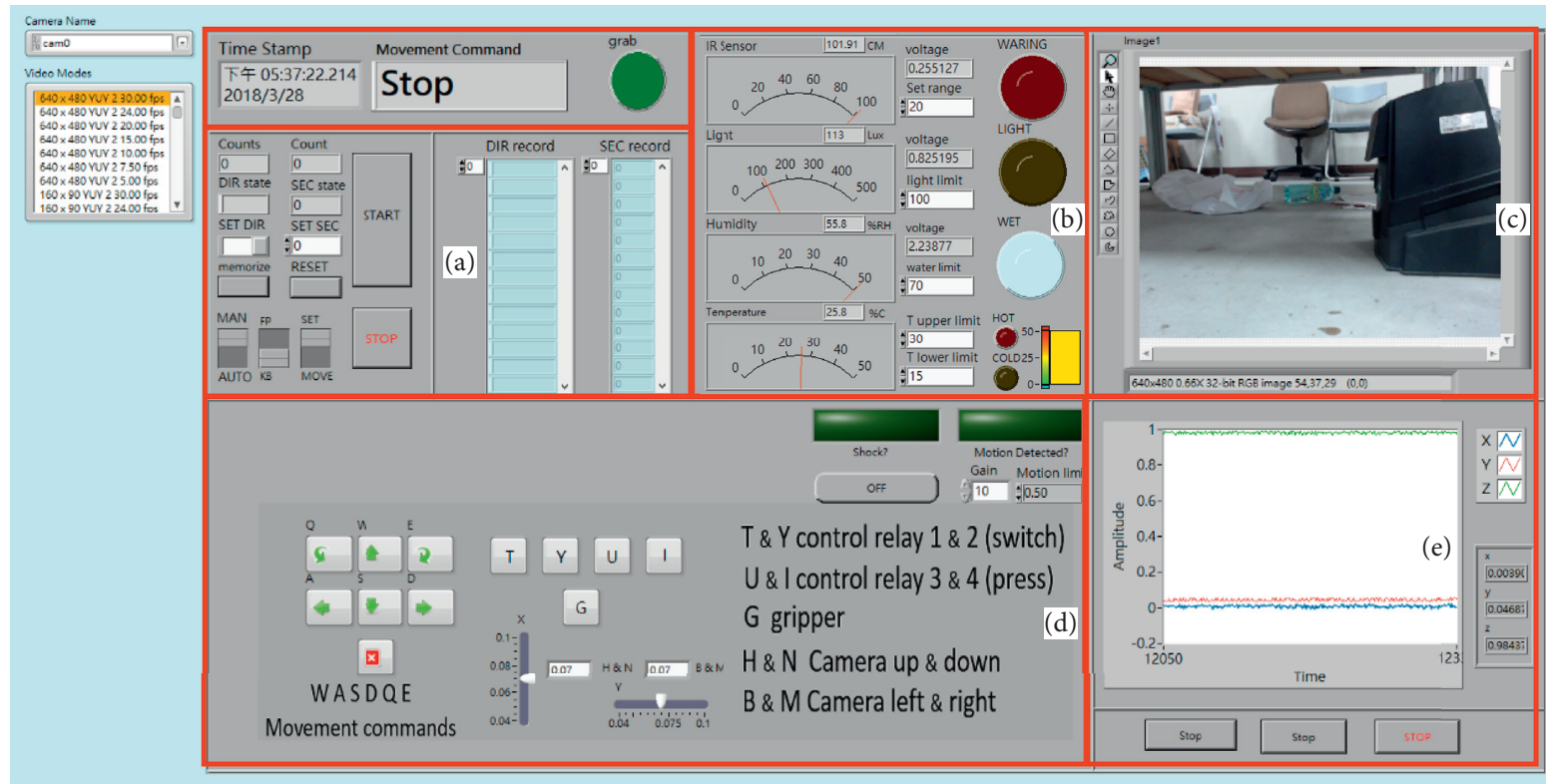

Figure 4: Front control and display panel of the robot.

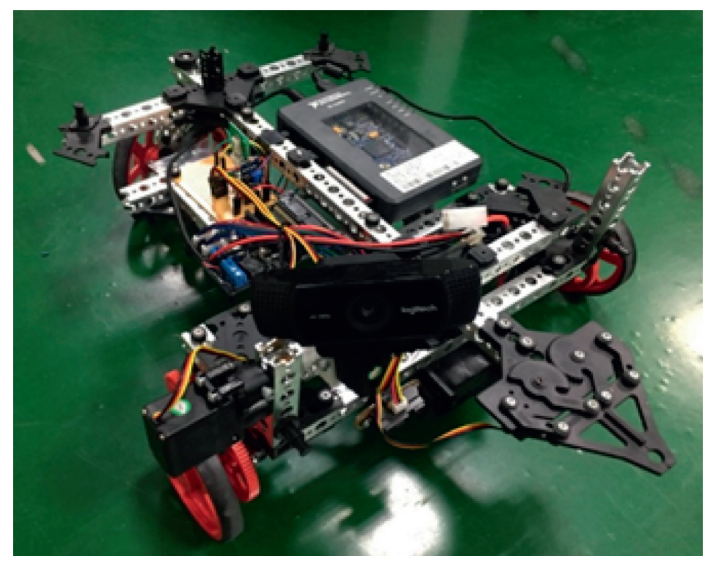

Figure 5: Exterior of the IoT smart home robot.

Following the schedule presented in Figure 6, the psychomotor and affective scale tests were conducted. The results are shown below. Following [22], the cited psychomotor and affective scales were revised and applied in this research. The psychomotor scale possessed a Kendall Harmony Coefficient of 0.885 , chi-square of 99.232 , and significance $p$ value (= 0.000 ) of less than 0.05 . The affective scale possessed reliability test Cronbach $\alpha$ of 0.928 . In this research, the psychomotor scale was integrated with technical capability indicators, comprising software design, use of the controller, hardware construction, software and hardware system integration, IoT technology practice, and system operation. This approach increased the accuracy of the psychomotor assessment scale. Moreover, in the affective scale, the subject teaching was changed to suit the IoT smart home robot.

4.3. Differential Analysis of Psychomotor Performance. Pre- and posttests were conducted to obtain the difference through the paired-sample $t$ test for determining the

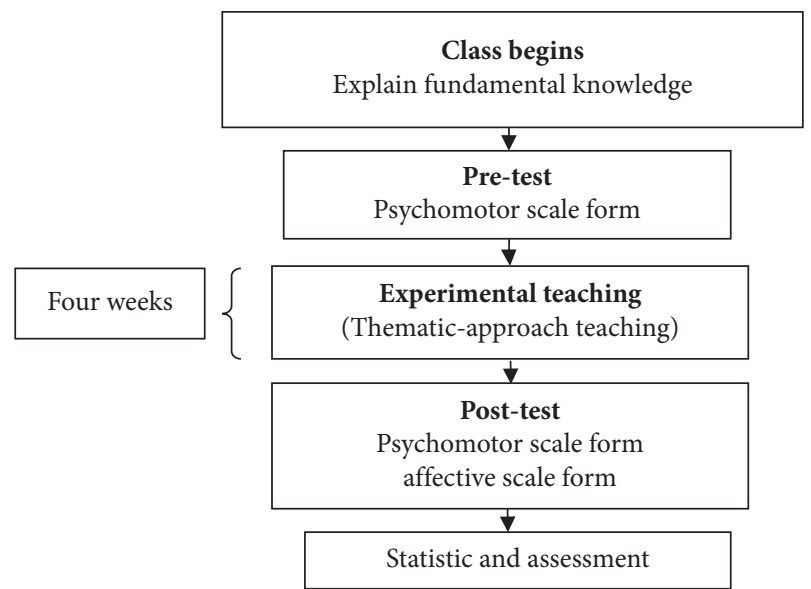

FIGURE 6: Schedule for the formal evaluation of psychomotor domain and affective domain.

effectiveness of the teaching material and equipment developed to enhance the students' skill performance. The psychomotor scale had a full score of 50, with the lowest score being 10. Table 3 presents the statistical results of the paired-sample $t$ test to determine the students' skill performance. Table 4 presents the difference between the two tests and the $t$ test results. As shown in Table 4, the differential mean value of the two tests was $M=-28.33$. Moreover, $t=-45.694, \mathrm{df}=38$, and the $p$ value reached significance at 0.001 . Thus, after taking this class, the students demonstrated significantly enhanced skill performance.

From the results, it is evident that the psychomotor performance of 39 students improved after receiving experimental teaching. In the posttest, the Kendall Harmony Coefficient was used to test the reliability of the skill evaluation; the Kendall Harmony Coefficient $(w)$ was 0.893 , and 
TABLE 2: Thematic IoT smart home robot teaching curriculum planning.

\begin{tabular}{lcc}
\hline Week & Units and progress & Remark \\
\hline 15th & Unit 1: Overview & Embedded thematic teaching \\
& Unit 2: IoT smart home robot technology & \\
\hline 16 th & Unit 3: IoT smart home robot system & Embedded thematic teaching \\
\hline \multirow{2}{*}{17 th } & Unit 3: IoT smart home robot system & Embedded thematic teaching \\
\hline \multirow{2}{*}{18 th } & Unit 4: Establishment and practice of IoT smart home robot technology & Embedded thematic teaching \\
& Unit 6: Assignments and challenges & Unit 5: Conclusion
\end{tabular}

*Supplement.

TABLe 3: Paired-sample psychomotor $t$ test results for thematic IoT smart home robot course.

\begin{tabular}{lccccc}
\hline Paired variables & N & M & SD & SE & T \\
\hline Pretest & 39 & 13.32 & 1.24 & 0.20 & 0.78 \\
Posttest & 39 & 41.65 & 4.87 & $-45.694^{* * *}$ \\
\hline
\end{tabular}

$p^{* * *}<0.001$

TABle 4: Paired-sample $t$ test.

\begin{tabular}{|c|c|c|c|c|c|c|c|c|}
\hline \multicolumn{9}{|c|}{ Paired difference } \\
\hline \multirow{2}{*}{\multicolumn{2}{|c|}{ Item }} & \multirow{2}{*}{ M } & \multirow{2}{*}{$\mathrm{SD}$} & \multirow{2}{*}{ SE } & \multicolumn{2}{|c|}{$95 \%$ CI } & \multirow[t]{2}{*}{$\mathrm{T}$} & \multirow[t]{2}{*}{ Df } \\
\hline & & & & & UL & LL & & \\
\hline $\begin{array}{l}\text { Paired } \\
\text { Sample }\end{array}$ & $\begin{array}{l}\text { Pretest } \\
\text { Posttest }\end{array}$ & -28.33 & 3.63 & 0.58 & -29.02 & -27.66 & $-45.694^{* * *}$ & 38 \\
\hline
\end{tabular}

CI: confidence interval; UL: upper limit; LL: lower limit. $p^{* * *}<0.001$.

chi-square was 99.101 . The $p$ value $(=0.000)$ was less than 0.05 , indicating that the scores of the three reviewers were significantly correlated and consistent.

Table 5 presents the average and standard deviation values of each level of the technical ability evaluation of the students who attended the subject-based IoT smart home robot course. The tested technical abilities comprise equipment assembly ability, equipment operation ability, integrated construction ability, and robotics-integrated construction design ability. The pairwise difference at a single level, that is, the ability to integrate technologies and build IoT smart home robot, showed the highest difference before and after learning.

4.4. Affective Scale Test. To understand the experimental group students' affective feedback on the teaching of the embedded IoT smart home robot, emotional attitude was assessed after experimental teaching by evaluating teaching material and equipment, cognitive development, skill performance, and self-exploration on a 5-point Likert scale. Table 6 presents the results. The reliability test for the official questionnaire had a Cronbach $\alpha$ of 0.902 . The highly rated items for different dimensions are described as follows: (i) In the teaching material and equipment dimension, the teaching material is well connected with the teaching and contains sufficient knowledge and practice. The content volume and difficulty level are appropriate. (ii) In the cognitive development dimension, the teaching material and experimental equipment stimulated personal learning motivation and interest, encouraging the development of new products. (iii) In the skill performance dimension, the teaching material and experimental equipment provided the students with practical support to meet the current learning demands of the industry and help advance their AI robot design abilities. (iv) In the self-exploration dimension, the course increased the students' practical experience in robot design and construction, enabling them to determine if they are a good fit for this professional field. Finally, the affective and psychomotor scales were also tested and confirmed; they possessed high reliability and validity.

Table 7 shows the average and standard deviation of the affective questionnaires of the students who received thematic learning of IoT smart home robot design and practice. The students reported a higher positive feeling in this component of skill performance.

Table 8 provides the average, standard deviation, and results of independent sample $t$ tests on the various levels of the student affective questionnaire on plans after graduation. It is shown that the students who planned to pursue higher education after graduation had significantly higher positive affective attitudes in the two dimensions of cognitive development and skill performance than those who planned to get employment after graduation. The survey also revealed 
TABle 5: Paired differences in various levels of technical ability assessment of students receiving the thematic learning of IoT smart home robot.

\begin{tabular}{|c|c|c|c|c|c|c|}
\hline Dimension name & $\begin{array}{l}\text { Question number } \\
\text { (D) }\end{array}$ & $\mathrm{N}$ & M & SD & $\mathrm{M} / \mathrm{D}$ & Rank \\
\hline The assembly capability of thematic IoT smart home robot equipment & 2 & 39 & -5.81 & 1.01 & -2.91 & 2 \\
\hline The operation capability of thematic IoT smart home robot equipment & 3 & 39 & -8.43 & 1.55 & -2.81 & 3 \\
\hline The ability to integrate thematic IoT smart home robots & 1 & 39 & -3.02 & 0.43 & -3.02 & 1 \\
\hline $\begin{array}{l}\text { The design capability of the integrated construction of thematic IoT smart home } \\
\text { robots }\end{array}$ & 4 & 39 & -11.07 & 2.07 & -2.77 & 4 \\
\hline Total & 10 & 39 & -24.62 & 3.89 & -2.833 & \\
\hline
\end{tabular}

TABLE 6: Thematic affective scale of IoT smart home robot course.

\begin{tabular}{|c|c|c|c|c|}
\hline No. & Item connotation & $\mathrm{N}$ & M & $\mathrm{SD}$ \\
\hline \multicolumn{5}{|c|}{ Dimension 1: teaching material and equipment } \\
\hline 1 & The teaching material content is & 39 & 4.23 & 0.57 \\
\hline 2 & The content volume and difficulty level are appropriate. & 39 & 4.45 & 0.62 \\
\hline 3 & The teaching material content is logical and well organized. & 39 & 4.18 & 0.38 \\
\hline 4 & The teaching material is well connected with the teaching. & 39 & 4.64 & 0.52 \\
\hline 5 & The teaching material and experimental equipment contain enough knowledge and practices. & 39 & 4.44 & 0.47 \\
\hline 6 & The teaching material and experimental equipment can clearly explain the experimental process. & 39 & 4.32 & 0.51 \\
\hline 7 & $\begin{array}{c}\text { The teaching material and experimental equipment can integrate other related professional knowledge to solve } \\
\text { problems. }\end{array}$ & 39 & 4.32 & 0.66 \\
\hline \multicolumn{5}{|c|}{ Dimension 2: cognitive development } \\
\hline 1 & al of each chap & 39 & 4.38 & 0.57 \\
\hline 2 & The teaching material can facilitate th & 39 & 4.35 & 0.49 \\
\hline 3 & The teaching material contains innovative skill content. & 39 & 4.28 & 0.52 \\
\hline 4 & aching materi & 39 & 4.43 & 0.53 \\
\hline 5 & The teaching material and experimental eq & 39 & 4.55 & 0.44 \\
\hline 6 & The teaching material and experimental equipm & 39 & 4.66 & 0.38 \\
\hline 7 & The teaching material and experimental & 39 & 4.68 & 0.46 \\
\hline \multicolumn{5}{|c|}{ Dimension 3: skill performance } \\
\hline 1 & Thematic IoT smart home robot & 39 & 4.77 & 0.34 \\
\hline 2 & Thematic IoT smart home robo & 39 & 4.30 & 0.52 \\
\hline 3 & Thematic IoT smart home robot course promotes $\mathrm{p}$ & 39 & 4.42 & 0.45 \\
\hline 4 & Thematic IoT smart home robot course can improve prac & 39 & 4.61 & 0.43 \\
\hline 5 & $\begin{array}{c}\text { Thematic IoT smart home robot course can help students improve their innovative development ability of robot } \\
\text { construction. }\end{array}$ & 39 & 4.62 & 0.37 \\
\hline 6 & $\begin{array}{l}\text { Thematic IoT smart home robot course teaching material and experimental equipment provide students with } \\
\text { practical support to meet the current learning demands of the industry. }\end{array}$ & 39 & 4.88 & 0.38 \\
\hline 7 & Thematic IoT smart home robot course promotes personal multidime & 39 & 4.72 & 0.41 \\
\hline \multicolumn{5}{|c|}{ Dimension 4: self-exploration } \\
\hline 1 & • & 39 & 4.52 & 0.62 \\
\hline 2 & parts professional $\mathrm{s}$ & 39 & 4.48 & 0.53 \\
\hline 3 & The skill training in this them & 39 & 4.63 & 0.55 \\
\hline 4 & This thematic course can help students understand $t$ & 39 & 4.58 & 0.58 \\
\hline 5 & This thematic course helps students understand if they are suited for this professional field. & 39 & 4.78 & 0.62 \\
\hline 6 & This thematic course increases students' practical experience in robot design and practice. & 39 & 4.67 & 0.48 \\
\hline 7 & This thematic course offers a professional advantage for future employment. & 39 & 4.53 & 0.60 \\
\hline
\end{tabular}

TABLE 7: The average and standard deviation of the affective questionnaires in individual dimension.

\begin{tabular}{|c|c|c|c|c|c|}
\hline Dimension & Question number & $\mathrm{N}$ & $\mathrm{M}$ & $\mathrm{SD}$ & Rank \\
\hline Teaching material and equipment & 7 & 39 & 4.37 & 0.53 & 4 \\
\hline Cognitive development & 7 & 39 & 4.48 & 0.48 & 3 \\
\hline Skill performance & 7 & 39 & 4.62 & 0.41 & 1 \\
\hline Self-exploration & 7 & 39 & 4.60 & 0.59 & 2 \\
\hline Total & 28 & 39 & 4.52 & 0.50 & \\
\hline
\end{tabular}


TABLe 8: Analysis table of $t$ test for students' attitude toward different graduation plans.

\begin{tabular}{|c|c|c|c|c|c|c|c|}
\hline Dimension & No. & $\begin{array}{l}\text { Graduation } \\
\text { plan }\end{array}$ & $\begin{array}{l}\text { Number of } \\
\text { people }\end{array}$ & Average & $\begin{array}{l}\text { Standard } \\
\text { deviation }\end{array}$ & $t$ & $p$ \\
\hline \multirow{2}{*}{$\begin{array}{l}\text { Teaching material and equipment cognitive } \\
\text { development }\end{array}$} & \multirow{2}{*}{7} & Graduate & 16 & 4.38 & 0.5211 & \multirow{2}{*}{1.647} & \multirow[t]{2}{*}{0.103} \\
\hline & & Employment & 23 & 4.36 & 0.5362 & & \\
\hline \multirow{2}{*}{ Skill performance } & \multirow{2}{*}{7} & Graduate & 16 & 4.55 & 0.5917 & \multirow{2}{*}{$3.692^{* * *}$} & \multirow{2}{*}{0.000} \\
\hline & & Employment & 23 & 4.34 & 0.4023 & & \\
\hline \multirow{2}{*}{$\begin{array}{l}\text { Teaching material and equipment cognitive } \\
\text { development }\end{array}$} & \multirow{2}{*}{7} & Graduate & 16 & 4.76 & 0.4170 & \multirow{2}{*}{$3.801^{* * *}$} & \multirow[t]{2}{*}{0.000} \\
\hline & & Employment & 23 & 4.60 & 0.4051 & & \\
\hline \multirow{2}{*}{ Skill performance } & \multirow{2}{*}{7} & Graduate & 16 & 4.62 & 0.6165 & \multirow{2}{*}{1.891} & \multirow[t]{2}{*}{0.110} \\
\hline & & Employment & 23 & 4.59 & 0.5716 & & \\
\hline \multirow{2}{*}{ Total } & \multirow{2}{*}{28} & Graduate & 13 & 4.54 & 0.5092 & \multirow{2}{*}{$2.902^{* *}$} & \multirow[t]{2}{*}{0.005} \\
\hline & & Employment & 23 & 4.50 & 0.4936 & & \\
\hline
\end{tabular}

$N=39 ; p^{*}<0.05 ;{ }^{* *} p<0.01 ; * * * 0.001$.

that the students who planned to study further after graduation had a higher overall positive experience than those who planned to get employment after graduation. It can be concluded that the students who wished to study further were more positive in terms of cognition and skills. The participants who choose to be employed might be less active in terms of course learning due to enrollment into military service or internships prior to employment. However, as can be seen in Table 8 , the overall feedback received on all levels of the sentiment questionnaire from the students who had taken the thematic courses in robot design and practice indicates a high rating.

\section{Conclusion}

In this study, we developed teaching material and equipment and performed curriculum planning for a thematic IoT smart home robot teaching module. In teaching equipment design, six technical capability indicators, namely, software design, use of the controller, hardware construction, software and hardware system integration, IoT technology practice, and system operation, were utilized to establish a psychomotor assessment scale. Moreover, in the affective questionnaire scale, four dimensions, namely, teaching material and equipment, cognitive development, skill performance, and self-exploration, were utilized to examine the students' feelings after learning. The reliability and validity of these two assessments were determined. As a teaching strategy, theme-based teaching was embedded to perform and evaluate the thematic IoT smart home robot teaching module. Based on $t$ test and descriptive statistical results, the psychomotor assessment revealed that the overall technical ability and skill levels of trainees were effectively improved. The affective assessment highlighted the individual importance of and difference between the 28 indicators of the four major aspects. Finally, the difference in the learning experiences of students with different career plans after graduation was examined.

\section{Data Availability}

All the data information has been described in the manuscript.

\section{Conflicts of Interest}

The authors declare that they have no conflicts of interest.

\section{Acknowledgments}

This study was funded by the Ministry of Science and Technology, Taiwan, under grant number MOST 109-2511H-018 -018 -MY3.

\section{References}

[1] I. D. C. FutureScape, Worldwide Robotics 2018 Predictions, International Data Corporation, Framingham, MA, USA, 2017.

[2] Ministry of Economy, Industrial Technology Foresight", Ministry of Economy, New Delhi, India, 2018.

[3] Ya-W. Cheng, P.-C. Sun, and N.-S. Chen, "An Investigation of the Needs on Educational Robots," in Proceedings of the IEEE 17th International Conference on Advanced Learning Technologies (ICALT), pp. 536-538, Timisoara, Romania, Balkans, July 2017.

[4] Department of Technology, Ministry of Economic Affairs, Industrial Technology White Paper 2019-2020, Department of Technology, Ministry of Economic Affairs, New Delhi, India, 2019.

[5] H. Jiang, C. Cai, X. Ma, Y. Yang, and J. Liu, "Smart Home Based on WiFi Sensing: A Survey," IEEE Access, vol. 6, pp. 13317-13325, 2018.

[6] E. Shailendra, P. K. Bhatia, and K. B. Praneet, "Analyzing home automation and networking technologies," IEEE Potentials, vol. 37, no. 1, pp. 27-33, 2018.

[7] National Instrument https://www.ni.com/zh-tw/innovations. html.4/15/2020.

[8] U. Ormanci and S. Cepni, "A thematic review of tablet-based science education studies," Journal of Education in Science, Environment and Health, vol. 5, no. 1, pp. 36-54, 2019.

[9] L. Wang, "Entrepreneurial narratives and concept teaching and learning," Industry and Higher Education, vol. 34, no. 1, pp. 24-35, 2020.

[10] R. S. Lufler, M. D. Lazarus, and J. J. Stefanik, "the spectrum of learning and teaching: the impact of a fourth-year anatomy course on medical student knowledge and confidence," Anatomical Sciences Education, vol. 13, no. 1, pp. 19-29, 2020.

[11] G. Tejedor, M. Rosas-Casals, and J. Segalas, "Patterns and trends in engineering education in sustainability: a vision 
from relevant journals in the field," International Journal of Sustainability in Higher Education, vol. v20, no. 2, pp. 360377, 2019.

[12] K.-C. Yao, T.-C. Wu, L.-C. Hsu, and W.-T. Huang, "Evaluating Thematic-Approach Teaching of Robot Design and Practice Course through Psychomotor and Affective Domains," ICIC Express Letters, vol. 13, no. 1, pp. 41-50, 2019.

[13] H. F. Al, "English Language Assessment in the Colleges of Applied Sciences in Oman: Thematic Document Analysis," English Language Teaching, vol. 7, no. 3, pp. 19-37, 2014.

[14] A. Sh. Yarullina and A. T. Araslanova, "Development of subject position as a condition for forming communicative competence of a future teacher," International Journal of Environmental and Science Education, vol. 11, no. 9, pp. 2311-2322, 2016.

[15] K.-chao Yao, W.-tzer Huang, J.-Shean Chiang, and K.-ping Yao, "Developing an industry-oriented automatic measurement technology course," ICIC Express Letters, vol. 8, no. 2, pp. 511-518, 2014.

[16] J. Hill and H. West, "Improving the student learning experience through dialogic feed-forward assessment," Assessment \& Evaluation in Higher Education, vol. 45, no. 1, pp. 82-97, 2020.

[17] D. Thomas, R. Moore, O. Rundle et al., "Elaborating a Framework for Communicating Assessment Aims in Higher Education," Assessment \& Evaluation in Higher Education, vol. 44, no. 4, pp. 546-564, 2019.

[18] J. Batten, T. Jessop, and P. Birch, "Doing what it says on the tin? A psychometric evaluation of the assessment experience questionnaire," Assessment \& Evaluation in Higher Education, vol. 44, no. 2, pp. 309-320, 2019.

[19] K. Smith, S. Finney, and K. Fulcher, "Connecting assessment practices with curricula and pedagogy via implementation fidelity data," Assessment \& Evaluation in Higher Education, vol. 44, no. 2, pp. 263-282, 2019.

[20] T. Saaty, "Decision making with the analytic hierarchy process," International Journal of Services Sciences, vol. 1, no. 1, pp. 83-98, 2008.

[21] D. Tanner and L. Tanner, Curriculum Development: Theory into Practice, Merrill, an imprint of Prentice Hall, Englewood Cliffs, New Jersey, 1995.

[22] K.-C. Yao and W.-T. Huang, "Course development of robot design and practice introduced by MyRIO," International Journal of Emerging Trends \& Technology in Computer Science, vol. 7, no. 4, pp. 16-24, 2018.

[23] J. Travis, LabVIEW for Everyone: Graphical Programming Made Easy and Fun. Kring, Jim, Prentice-Hall, Upper Saddle River, NJ, USA, 3 edition, 2006.

[24] "From Student to Engineer: Preparing Future Innovators with the NI LabVIEW RIO Architecture," http://www.ni.com/ white-paper/52093/en/, 2020/3/15.

[25] G. Juan, "Parada-salado, "A low-cost land wheeled autonomous mini-robot for in-door surveillance," IEEE Latin America Transactions, vol. 9, pp. 1298-1305, 2018.

[26] K.-chao Yao, W.-tzer Huang, Y.-mao Wang, and Li-chiou Hsu, Establishing a Smart Home Based on NI Myrio", 2017 International Conference on Mechatronic,Automobile, and Environment Engineering, Yantai, China, 2017.

[27] "Machine Vision Projects with NI myRIO," Ftp://ftp.ni.com/ evaluation/academic/myRIO_Vision_Labs\%20_Preview.pdf, 2020.

[28] Y. Angal, "LabVIEW controlled robot for object handling using NI myRIO," IEEE International Conference on Advances in Electronics, Communication and Computer Technology, vol. 2-3, pp. 167-171, 2016.
[29] S. D. Ruben, "Respect the implementation: using NI myRIO in undergraduate control education," American Control Conference, vol. 6-8, pp. 7315-7326, 2016.

[30] T. Caldeira, "MyRIO based mobile robot for rescue competitions," in Proceedings of the International Conference on Autonomous Robot Systems and Competitions, pp. 26-28, Coimbra, Portugal, April 2017.

[31] R. Y. Cavana, B. L. Delahaye, and S. Uma, Applied Business Research, Qualitative \& Quantitative Methods 1st edition: John Wiley and Sons Ltd, Hoboken, New Jersey, 2001.

[32] B. S. Bloom, Taxonomy of Educational Objective, David Makay Company, Pennsylvania, USA, 1956. 